\title{
ALGUNES BASES PRE-ROMÀNIQUES EN LA TOPONÍMIA DEL PIRINEU MEDITERRANI
}

\author{
Enric Guiter
}

Al col-loqui de toponímia organitzat a Dijon pel maig de 1981 sobre el tema «L'onomàstica, testimoni de les llengües desaparegudes», vam parlar de «Quelques bases toponymiques préromanes des Pyrénées méditerranéennes»'. L'abundància de la matèria i l'espai de temps concedit a cada ponència, van limitar la nostra a les bases, començant per les dues primeres lletres de l'alfabet, $A$ i $B$. L'interès que sempre ha manifestat el nostre amic Frederic Udina per aquest gènere d'investigacions ens incita, en el present estudi que se li dedica, a prosseguir-les amb les lletres inicials seguients, $C$ i $D$. Tanmateix, la facilitat amb la qual les parles pirinenques passen de les consonants oclusives sordes a les sonores corresponents, ens duu a no distingir $K / G$ d'una part, i $D / T$ de l'altra.

Alguns sufixos sovint tenen el valor de posposicions carregades plenament d'un contingut semàntic; per aquest motiu no els deixem de banda.

\section{K/G}

\section{KALE}

Aquest sufix apareix prou sovint en els documents antics del Baridà, de la Cerdanya, Vall de Ribes, del Conflent, Besalú i Rossell $6^{2}$.

El grup es troba escassament a les inscripcions ibèriques: arrikalerka, dubasikaleika.

I HenRa GuTtER, Quelques bases toponymiques préromanes des Pyrénées méditerranéennes. Dijon, L'onomastique témoin des langues disparues, 1982, p. 163.

${ }^{2}$ HENRI GUTTER, Manifestations de substrat basque dans la toponymie des Pyrénées orientales. París, Actes du $86^{\circ}$ Congrès National des Sociétés Savantes, 1961, p. 337.

HeNri GUTrER, Les suffixes de localisation dans la toponymie des Pyrénées orientales. Florència, Actes du $7^{e}$ Congrès International d'Études Onomastiques, 1961, II, p. 109. 
Ens acontentarem amb la confrontació de dues sèries de tres exemples cadascuna que posen en relleu una doble evolució fonètica bastant curiosa:

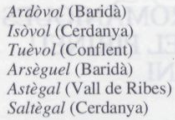

\author{
Ardocale en 890 \\ Isogal en 1011 \\ Tobecale en 864 \\ Arcegal en 839 \\ Estegal en 1044 \\ Saltegal en 839
}

En les atestacions de l'edat mitjana el sufix es presenta, o bé sota la forma arcaica - kale, o bé sota una forma regularment més evolucionada, amb sonorització de la sorda intervocàlica i caiguda de la e final, és a dir-gal.

Els tres darrers noms moderns de la llista ens ensenyen una conservació gairebé integral d'aquest sufix, fins i tot si les grafies difereixen lleugerament; evidencien el fet que es tracta d'un sufix àton.

Però els tres primers termes moderns presenten un sufix àton - bol al lloc del sufix - gal esperat. Haurem d'admetre que va haver-hi substitució capritxosa de sufix? Ens sembla poc probable si considerem que la mutació no és agrupada dins l'espai, i es troba del Baridà al Conflent amb intercalació de formes en-gal. Preferentment ens decantaríem per un canvi fonètic. El final -bol apareix en toponims que presentaven una $o$ radical; resulta molt probable que hi hagi hagut dilació del timbre $o$ a la vocal sufixal $i$, després labialització de la consonant per assimilació: la velar $g$ dóna en primer lloc la labio-velar $w$, i després la labial $b$ aspirant.

Queda per determinar el valor semàntic del sufix -kale. Podríem ser temptats pel sufix idèntic del basc modern -kale, que posseeix els sentits de «entre, entremig ${ }^{3}$. Però es presenta una dificultat fonètica. La $l$ intervocàlica del basc antic s'ha tornat $\mathrm{r}$ en basc modern, salvat el cas que hagi deixat de ser intervocàlica per apòcope de la vocal final. Això ens condueix a vacil-lar entre dos termes: gare «graner, dipòsit» $\mathrm{i}$ - kal «en relació amb, en proporció amb, pers.

Havíem notat que alguns radicals associats amb -kale recordaven noms d'animals domèstics: ardi, "ovella»; asto, «burron; zaldi, «cavall»... Però aquesta observació no té un caràcter general.

\section{KAN}

Diversos topònims que corresponen a una elevació del sòl més o menys important, ofereixen una síllaba inicial $\mathrm{kan}^{4}$. Sembla relacionada amb el

${ }^{3}$ R.M. DE AzkuE, Diccionario vasco-español-francés. Bilbao 1903, I, p. 463. 
basc gain/ gan, «cim, cima, altura, puig»; la sonorització de la consonant sorda inicial és regular en base modern.

El grup kan es presenta freqüentment en les inscripcions ibèriques: bimbesarrikan, garokan, biukandaba, ganega ...

\section{Canigó}

A 40 quilòmetres de la costa mediterrània, el Canigó aixeca el seu cim a una altitud de 2.785 metres; aquest canvi violent de nivell li va valer de ser considerat antany com el punt culminant del Pirineu.

Les atestacions de l'edat mitjana (a uertice Canigonis en 875, in cacumine montis Canigonis en 937, in monte Canigone en 950, etc.) ens remeten a una forma antiga kaniko, on va haver sonorització de la consonat sorda intervocàlica $i$ introducció en la declinació llatina amb assimilació de la $o$ final al sufix -one.

No es pot deixar de pensar en el basc modern gaineko, «superior, el que està al punt més elevat» o ganeko, «sobre, al damunt de».

S'ha d'explicar la $i$ medial de Canigó, Una $e$ basca només pot donar $i$ sota l'acció d'una yod'; aquesta existeix en la forma gaineko, i hem d'admetre que s'hagi transposat de la primera a la segona silllaba: així va poder exercir la seva acció sobre la $e$, i no sobre la $a$.

El terme gaineko és un genitiu de situació del mot de base gain.

\section{Canet}

En el domini català es troben una desena de llocs que porten el nom de Canet. Alguns han tingut la temptació de relacionar-los amb el llatí canna, "canyas ${ }^{6}$. Efectivament el sufix - etu sovint s'afegeix a noms de vegetals; però no sempre (cf. Pedret). En el cas present, existeix una dificultat fonètica que no es podria superar: en català, com en espanyol, la $n$ doble llatina dóna una $n$ palatal; un lloc on abunden canyes es diu canyar, canyer o canyet.

Les mencions antigues presenten sempre una $n$ senzilla, i també manifesten que es tracta d'un sufix -etu (i no-ittu), perquè no trobem mai $t$

${ }^{4}$ Henri Gurter, Les bases oronymiques préromanes sur les Pyrénées méditerranéennes. Logroño, $6^{\circ}$ Congrès International d'Études Pyrénéennes, publié par Cuadernos de Imvestigación Ftlológica, 1975, 2, p. 35.

5 Henri GuTrer, Vocalisme des toponymes préromans sur les Pyrénées orientales. Londres, Actes du $9^{e}$ Congrès International d'Onomastique, 1966, p. 252.

6 AlCOVER i MolL, Diccionari catald-valencid-balear. Palma de Mallorca 1961. 
doble, sinó al contrari, exemples de $t$ sonoritzada en $d$ entre vocals: uila kanedo (1016), uila de Canet (1029), in Caneto (1041), de Caned (1087), de kaned (1091), etc.

Hem pogut constatar que els Canet que coneixem, fins quan són veïns de les vores del mar, no se situen en baixos humits, favorables a la multiplicació de les canyes, sinó sobre altures que dominen els entorns.

El Canet de Rosselló, a 2,5 quilòmetres de la riba actual del mar, ocupa l'extremitat oriental d' un moll llarg d'uns 7 quilòmetres des de la sortida de Perpinyà; la seva altitud varia entre 50 i 20 metres. El mapa a l'escala de $1 / 25.000$ de l'sInstitut Géographique National» indica les altituds: $20 \mathrm{~m}$ al cementiri de Canet, $8 \mathrm{~m}$ a $500 \mathrm{~m}$ al nord-oest, $8 \mathrm{~m}$ a $500 \mathrm{~m}$ al nord, $6 \mathrm{~m}$ a $500 \mathrm{~m}$ al nord-est, $6 \mathrm{~m}$ a $500 \mathrm{~m}$ a l'est. $6 \mathrm{~m}$ a $500 \mathrm{~m}$ al sud-est. $5 \mathrm{~m}$ a $500 \mathrm{~m}$ al sud, $6 \mathrm{~m}$ a $500 \mathrm{~m}$ al sud-oest, i $26 \mathrm{~m}$ a $500 \mathrm{~m}$ a l'oest, en direcció de Perpinyà. Aquesta repartició d'altituds ensenya bé la situació dominant de Canet sobre la plana litoral.

Més al nord, sobre els turons que separen les valls de l'Auda i de l'Arieja, un altre Canet és un lloc del municipi de Sant Benet (cantó de Xalabra).

\section{Candell}

Candell és un llogarret del municipi de Caixàs (cantó de Tuïr). Les mencions medievals del topònim ens ensenyen que es tracta d'un derivat en -ellu de Canet: Canetellum (845), Candello (872), Candel (1172).

L'evolució fonètica és perfectament regular: sonorització de la $t$ intervocàlica, caiguda de la $e$ contrafinal, manteniment del grup nd secundari i palatalització de $l$ doble. Mentre que Caixàs o el llogarret veí de Fontcoberta se situen a altituds inferiors a $400 \mathrm{~m}$, Candell s'aixeca sobre una cadeneta muntanyosa que culmina a $694 \mathrm{~m}$.

Dos altres topònims, Canadell i Canidell, en els quals la vocal contrafinal s' ha mantingut amb fortunes diverses, s'han d'afegir aquí.

Canadell és un lloc del municipi de Sant Joan les Fonts, al nord d'Olot. Ocupa un moll de 500 a $600 \mathrm{~m}$ d'altura entre les valls del Fluvià i del seu afluent, la Riera de Carreres, l'altitud dels quals només abasta de 200 a $300 \mathrm{~m}$.

Més modest és el Canadell del municipi de Clairà, al Rosselló.

El plural Canadells és un lloc del municipi de Reinès, prop de Ceret, mencionat en singular en 1121. També és un lloc del municipi de Costuja, cantó de Prats de Molló.

Canidell és el nom d’un moll penyalós al sud de Prats de Molló; separa dos rius $\mathrm{i}$ un dels quals ha pres el seu nom. 
En domini llenguadocià, la $e$ tònica pot reduir-se a $i$ després de diftongar, d'on Candilla (municipi de Brenac). També hi apareixen derivats Candelleres als municipis de Terroles i de Vinyavella.

\section{Cànoa}

Aquest topònim es presenta sota la forma d'un singular romànic Cànoa (municipi de Prada) o del plural corresponent, Cànoes, poble veí de Perpinyà.

Els dos llocs estan situats sobre altures. A propòsit de Cànoa, P. Vidal escriu: «[La route] monte ensuite et contourne le gros promontoire qui cache la vallée de la Castellane. Cette partie du territoire s'apelle Canoues (sic); c'était le nom d'un petit village dont l'église de Saint-Martin est encore debouts.

Cànoes ocupa l'extremitat nord-oriental d'un moll d'altitud 80 metres, voltat per Toluges $(60 \mathrm{~m})$ al nord, el Mas de les Coves $(54 \mathrm{~m})$ a l'est, Pollestres $(43 \mathrm{~m})$ al sud-est, Nils $(51 \mathrm{~m})$ al sud.

L'etimologia casas nouas proposada pel $\mathrm{DCVB}^{8}$ no sembla convenir, en primer lloc, perquè l'accent del sintagma hauria recaigut sobre la $o$ de l'adjectiu, i no sobre la $a$ de la síl-laba inicial; després, perquè les $s$ intervocàliques que s'emmudeixen, no ho fan abans del segle XI; ara bé, una donació del 843 concedida per Carles el Calb a Sunifred de Cerdanya (publicada tant en Marca Hispànica com per B. Alart o R. d'Abadal) ens presenta la forma Kanoas per Canoes. Tornem a trobar Canoas en 1102 i 1119, Canues en 1146, Chanues en 1112, Canoys en 1090, etc.

Igualment per Cànoa tenim la mateixa forma Canoa en 985, 1119. 1300, 1308, etc. Tanmateix, notem Canoua en 850 , i en 1011 sobre un mateix document terminum de Canoua uel Petrafixa [...] alodem de Canodia; $\mathrm{el} 855$ llegim in uilla Cannoiias, el que ens condueix a demanar-nos si la lectura $u$ no correspon a dues $i$ antihiatiques.

La reducció a dues vocals del final àton dificulta la recerca d'una etimologia. Les mencions amb $i$ o di intercalats poden fer suposar un estadi palatal, i la palatal sonora s'emmudeix entre postònica i final (CF. Lauredia $>$ Lòria). Es pot pensar en el base odia, «barranc» $\mathrm{o}$ oian, *bosc» (la $n$ final és caduca).

AJ Narbonès, el nom de Canà (Lo Cana en 1781) ${ }^{\circ}$, al sud-oest del poble de Peyriac de Mar, és possiblement parent dels que acabem de veure.

${ }^{7}$ PIERRE VIDAL., Guide Historique des Pyrénées-Orientales. Perpinyà 1899.

\& Alcover i Mol., Diccionari català-valenciá-balear. Palma de Mallorca 1961.

${ }^{9}$ AвBÉ S ABARtHEs, Diccionaire topographique du département de l Aude. Paris 1912. 


\section{Canillo}

Canillo és el nom de la parròquia del nord-est d'Andorra, la més alta $(1.531 \mathrm{~m})$. La dominen al nord i a l'est muntanyes molt altes (Pic de Serrera, $2.911 \mathrm{~m}$; Pic de Menilmenut, $2.735 \mathrm{~m}$; Pic de Fontargenta, $2.786 \mathrm{~m}$; Pic de la Cabaneta, $2.841 \mathrm{~m}$; Pic d'Envalira, $2812 \mathrm{~m}$ ) que separen la conca del Valira de la conca de l'Arieja, és a dir la conca de l'Ebre de la del Garona. Una carretera recent tramunta aquella barrera al port d'Envalira (2.407 m).

L'atestació més antiga és Kanillaue (839); en 1176 la $e$ final desapareix i trobem Canilau; la $a u$ final àtona es redueix a $o$. Sembla que la forma primitiva pugui descompondre's en kan-illa-be, «sota el cim difícil (d'accés)».

Una complicació fonètica és el manteniment del timbre de $i$, que normalment té el tractament de $i$ breu romànica, i que esdevé $e$, si no la segueix cap yod. Possiblement la romanització d'aquella vall molt apartada va ser prou tardana, i la mutació de timbre havia deixat de produir-se.

\section{Canelles}

Aquest vocable designa una collada de l'Albera entre els termes d'Argelers i de Banyuls de la Marenda. En tenim atestacions antigues: Canelias (881), usque ad collum de Canellas (981).

Un altre Canelles, llogarret del municipi de Navata, prop del riu Fluvià, és anomenat Canellas des del 878.

Sobre les eminències de la Corbera, veiem dos Canelles, en els termes municipals de Sant Joan de Barró i Palairac (alodium de Canellas 1521).

En singular, Canella designa un pic alt de $546 \mathrm{~m}$ (municipi de Davejà). i una selva del municipi de Niort. També és un topònim del municipi de Sant Salvador de Vianya.

El diminitiu Canelleta és un lloc del municipi de Camps.

És molt possible que es tracti encara d'una altura d'accés difícil. La situació dels topònims exclou una relació amb les canyes.

\section{Cameles}

Cameles és el nom d'un poble de la part alta del cantó de Tuïr $(350 \mathrm{~m})$ mencionat en 950 amb la grafia Camelas. Aquest nom podria ser l'equivalent del basc modern gan beratz "praderia d'adalt». La forma antiga *kan belatz hauria seguit l'evolució *kambelas i kamelas. 


\section{Canavelles}

Aquest nom és el d'un poble del cantó d'Oleta. Està quitllat a dalt dels penya-segats que voregen al nord la vall de la Tet. La primera menció que coneixem, Canauella, és del 846, forma repetida en 847, 864, 868, 871, 874,878 , etc. Aquelles atestacions nombroses del segle IX ens semblen eliminar l'etimologia Casas nouellas proposada pel DCVB ${ }^{10}$. Endemés, aquest mateix terme designa una muntanya veïna de les Illes (cadena de l'Albera), el Serrat de la Canavella, a pocs quilòmetres d'una aitra muntanya anomenada Roca Negra.

Pensem que en aquests topònims la base kan va associada a l'adjectiu beltz, «negre». Notem que el basc bela, «corb», de la mateixa arrel, suposa una antiga $l$ doble, que havia de palatalitzar-se regularment en català.

\section{KARRI}

Aquesta base és relacionada amb el base harri, «pedra». El gup karri apareix a les inscripcions ibèriques: koloitekarri, turbidukarrin, bitekarrine...

Si la $i$ va seguida d'una vocal, el hiatus la tanca en yod, que es transposa al contacte de la $a$, i tanca aquesta en $e$. Tal accident passarà particularment amb la forma definida (karria dóna quera) o amb la forma indefinida proveïda d'una vocal temàtica romànica u (karriu dóna quer).

\section{Carlit}

El punt culminant del Pirineu oriental $(2.921 \mathrm{~m})$ no posseeix, que sapiguem, atestacions antigues. Voltat per altres muntanyes elevades, no es veia gaire des de les regions habitades $i$, doncs, no podia servir de senyal (al contrari del Canigó). El seu nom pot representar karri-lei-to, «gel gros en la pedra»; el cim pedregós del Carlit és molt fred, a causa de la seva altitud.

\section{Carcolze}

El nom d'aquesta masia del municipi d'Aristot (Barida) ja apareix en 839 sota les formes Karchobite o Charcoude, i en 964 Carcolde. La primera part de karchobite sembla una contracció del genitiu karriko, «de

10 Atcover i MOL, Diccionari català-valencid-balear. Palma de Mallorca 1961. 
la pedra»; la segona equival al basc bide, «camí; el conjunt significa «camí de la pedras. Carcolze és sobre el trajecte que va de la vall del Segre a les muntanyes d' Andorra.

L'evolució fonètica de karrikobite a Carcolze s'explica facilment.

L'accent romànic va portar sobre la vocal $o$; primer, va caure la $i$ contrafinal, d'on karkóbite: després, sonorització de la $t$ intervocàlica, karkóbide; caiguda de la $i$ posttònica, karkóbde; semivocalització de la $b$ implosiva, karkoude; falsa regressió de $w$ a l, karkolde (la mateixa cosa que va passar en malhab(i)tu/malaut/malalt); assimilació de la $d$ en $z$ (com en cub(i)tu/colde/ colze).

\section{Pincaró}

Aquest lloc del municipi de Bassegoda és mencionat el 878 sota la forma Pino Karkone. És identificat en romanç per un «pi», sense dubte remarcable en aquell temps, i per un terme pre-romànic karkone, versemblantment contracció de karriko une, «interval de pedra».

\section{Carcanet i Campcardós}

Les dues bases karri i kan s'uneixen naturalment en alguns topònims designant «altures pedregoses».

El Carcanet és la regió oriental del Donesà, on l'Auda talla la carena pirinenca relligant el massís del Peric al del Madres, entre penya-segats molt alts. El mateix topònim torna a aparèixer molt més al nord, al terme municipal de Ladern.

El poble donesanès més veí del Carcanet porta el nom de Carcanieres, amb un sufix -ariu, al lloc de -etu. Notem que el Capcir i la Cerdanya anomenen "carcanet" el vent fred del nord-est que bufa en provinença del Carcanet.

La muntanya del Campcardós $(2.914 \mathrm{~m})$ ha tingut el seu nom explicat com a «camp de cards» " ; només pot haver-hi una falsa etimologia popular. Vam tenir ocasio d'anar al Campcardós a l'agost de 1933, i fins li vam consagrar un rondell ${ }^{12}$. De cap manera la cresta de la muntanya no pot donar la impressió d'un "camp"; és mancada totalment de vegetació i, més particularment, de cards, planta que abunda a altituds molt més baixes. Campcardós podria representar kan-karr(i)-otz, «altura pedregosa fredan,

11 Al.COVER i MOL... Diccionari català-valencià-balear. Palma de Mallorea 1961.

12 HENRI GUITER, Tardorenques, Barcelona, Dalmau, 1969. 
amb la mateixa equivalència $r d / r r$, que trobem en cerdo/txerri, isard/sarri, etc.

Notem que al Llenguadoc les formes en kayr, tals com Belcaire (Bellicadro 1347) o Cancairole (segle XVIII), llogarret de Santa Coloma de l'Hers, representen quadrum, i no karri.

\section{Quer. Quers}

El terme karri proveît d'una vocal temàtica romànica $u$ dóna les formes masculines karriu, karrios.

El Quer, a l'oest de Montboló (Vallespir) es presenta sota la forma kairum en 878; el mateix nom designa un lloc del municipi d'Eine, i una penya a l'est de la parròquia andorrana d'Encamp.

Al Llenguadoc la e diftonga (cf. pomariu dóna: cat. pomer, occit. pomier).

Quier és un topònim dels municipis de Lo Vivier, Prunyanes, Motomet (Al Quier 1538); hi ha un poble de Quier sobre la riba esquerra de l'Arieja.

En plural, Quers, amb la mateixa forma des del 1243, és un llogarret del municipi de La Tor de Carol; també es troba als termes municipals de Marquixanes i Finestret (menció del 1467) al Baix Conflent.

Si entra en composició, Quers guarda aquesta mateixa forma quan porta l'accent, com en Dosquers (Duobus queriis al segle XII), poble empordanès; Cadaqués, un altre poble empordanès; i també llocs de Prats de Molló i Argelers o Valldequers (1599), barranc al sud de Prats de Molló. Donem aquesta precisió perquè en posició àtona competeixen les grafies quer i car, que tenen la mateixa pronúncia.

\section{Queralt. Quirbajó. Queribús}

La vitalitat de Karriu ha estat tal que ha pogut associar-se amb adjectius romànics. El pic de Queralt, a l'oest d'Aransa (Baridà), és mencionat Cheralt en $1050 \mathrm{i} 1095$, Cheralto en 1134 . Al Llenguadoc una muntanya de Quiraut (Locus de Querio Alto, segles XII a XVII' ${ }^{13}$ se situa al terme del poble de Quirbajó (Locus de Queriobaione al segle XIII; Bastida de Queribais 1371-1589). Aquesta oposició d'alt i d'un derivat de baix ens permet d'interpretar el topònim Carbajó del municipi de Pi al Conflent. Prop de la frontera llenguadociana tenim un lloc de Carau al terme de Molig, i un lloc de Carmajó al terme del poble veí de Campome. Aquest Carmajó és

13 AвBé SABArthes, Dictionnaire topographique du département de l'Aude. París 1912. 
versemblantment el Carbajo corresponent a Carau, víctima d'una falsa etimologia popular.

La dimensió d'una penya es manifesta amb Carllong al poble de Serdinyà; la forma, amb Caràngol sempre a Serdinyà, Carangle (usque ad Chero Anglo en 937) a Canavelles, i possiblement Caragules a Sant Llorenç de la Cabrarissa (Narbonès).

Al nord de Portè, sobre la cadena pirinenca principal, el cim del Querforc s'aixeca a $2.650 \mathrm{~m}$.

El nom de Queribús es presenta dues vegades al Llenguadoc veí; és un lloc del poble de Sant Policarp, prop de Limós, i més que més, un castell medieval que s'aixeca al cim d'una penya de la Corbera. Tenim les mencions Cherbucio en 1021, Querbus i Querbutio en 1255, Querbusio en 1360, Querybus en 1538.

Es veu que la inserció de $i$ entre $r$ i $b$ per svarabhakti és un accident recent. El vocable pot representar $\operatorname{karri}(u)$ busi $(u)$, «tall de pedra».

L'eminència fortificada de Cremansó, prop de Vilajuïga, apareix sota les formes Carmazono en 1085, Charmezo en 1138, Carmenzo en Desclot, a finals del segle XIII; es pensa en karri mazo, "pedra rodona i forta", amb una interversió tardana del grup ar de la síl.laba inicial.

Al Fenollet, el poble de Caramany, ben anomenat per la seva roca enorme, té, segons $\mathrm{P}$. Vidal ${ }^{14}$ una atestació kero magno del 1395. També es troba un mont Quermany prop de Vilajuïga.

Altres qualificatius es refereixen a detalls més particulars. Un llogarret del poble de Real (Capcir), Odelló de Caramat és designat en 1011 uillarunculum quem uocant Odelonem de Cheroramatum; el mont de Caramat, que li serveix de determinant, és atestat en 908.

Al Baridà, Querforadat és un llogarret del municipi de Cava.

Al Conflent, prop de Canavelles, el Querescolat ja és Cherescolat en 847.

A Querigut, nom de la capital del Donesà, respon un Quirigou del municipi d'Albàs, al Narbonès.

La llarga vall estreta de Querançà, al territori de Fontpedrosa, a dalt del Conflent, té la menció karançano en 961; es pot pensar en un adjectiu anteanu, a causa del fet que les parets pedregoses s'avancen fins al mateix llit de la Tet.

\section{Querroig. Quercorb}

La base karri pot rebre com a epítet un nom de color. Així trobem un Querblanc (chero blanco en 1035) a Angostrina (Cerdanya) i un Quernegre a Corsavi (Vallespir).

14 Pierre Vidal, Guide Historique des Pyrénées-Orientales. Perpinya 1899. 
El color roig es presenta amb matisos diversos. En primer lloc, els hereus de rubeu amb tres Querroig: I'un damunt de Banyuls de la Marenda (pogium Cariorubio en 981); un altre damunt de Merens, a la riba esquerra de l'Arieja; un tercer més avall del mateix costat de l'Arieja, al terme de Lapeja. Podríem afegir-ne un altre més a l'Empordà, si l'antic Cairo Rubio del 957, al nord-oest de Viure, no s'hagués romanitzat del tot en Mont-roig. Un altre matís, el de russu, apareix amb el Carrós a mig cami entre l'Hospitalet d'Andorra i la frontera andorrana. Encara un altre matís amb rubinu en Carrubi, massís muntanyós entre Rocafort de So i Santa Coloma de Gueta (Al Carruby en 1594).

Creiem que el color roig encara està present en Quercorb, que trobem quatre vegades. Naturalment, les llatinitzacions tardanes han representat corb per curuu. Però veiem en domini basc formacions tals com Aizcorbe, «sota la penya roja» (Navarra); el topònim biscaí Arrigorriaga té el mateix adjectiu, però no el mateix sufix. Interpretem, doncs, Quercorb com karri(u)-korr(i)-be, usota la pedra roja». Quercorb és un lloc del municipi d'Arles de Tec (Curco Curbo en 981, Kero Curuo en 1197); també és la capital històrica de l'actual cantó de Xalabra (Cairocurbum en 1002, Keircorb en 1095). Sota la forma Quiercorb (Quier courb en 1594) és un lloc del municipi de Niort, i també (Quar Corp en 1355) del municipi de Ribauta.

Una situació contrària apareix amb Queralps, que trobem tres vegades: el poble del nordest de la Vall de Ribes (Keros albos i Chers Albs en 839, Cheros Albos en 978 i 1030, Queralbs en 1283); un lloc del municipi de Sansà, al nord-oest del Conflent; un lloe al sud de la Selva de Mar (ipsam Pennam quae est super Cheros Albos en 1063, que ens va valer al segle X una història divertida ${ }^{15}$. Aquí la llatinització ha percebut la síl laba final com si fos l'adjectiu llatí significant «blane»; però albu ha mantingut el seu valor llatí només en romanès i en sard. Pensem que alb, que es troba en molts altres topònims, té el sentit de ependent herbós» ${ }^{16}$.

No coneixem mencions antigues del pic de Quermals $(1225 \mathrm{~m})$ al municipi de Santa Coloma de Gueta; però és molt versemblant que la segona síl-laba, com la de Puigmal, correspongui a un «pendent estèril i pedregós s?

15 HENRI GUTTER, *Quelques curieuses modifications de désignations toponymiques dans les documents carolingiens des Pyrénées orientales», Revue des Langues Romanes, 1964. p. 22.

${ }^{16}$ HenRI GUTrer, Les bases oronymiques préromanes sur les Pyrénées méditerranéennes. Logroño, $6^{\circ}$ Congrès International d'Études Pyrénéennes, publié par Cuadernos de Investigación Filológica, 1975, 2, p. 35.

17 HeNRi Gutrer, Les bases oronymiques préromanes sur les Pyrénées méditerranéennes. Logroño, $6^{C}$ Congrès International d'Études Pyrénéennes, publié par Cuadernos de Investigación Filológica, 1975, 2, p. 35. 


\section{Quera. Queres}

La forma definida karria ha pres valor de femení en romanç.

Llocs dits La Quera es troben a Osseja (ipsa Chera en 815), a Casafabre i a Sant Llorenç de Cerdans (ipsa Caira en 936; in manso de Chera en 1168).

Saquera (Fenollet) manté l'hereu de l'article ipsa (Saccaria en 1011).

Bolquera (Cerdanya) proporciona un determinant a karria, el que esdevé buru en basc modern (Bolcharia en 876 ).

Les Queres i el Prat de les Queres a Montferrer (Vallespir), Les Esquerres, amb una aglutinació d'article, a Enveig i Angostrina (Cerdanya) no posseeixen atestacions antigues.

Querol. Querols. Querola. Queroles

Els derivats de karri amb sufix -olu semblen particularment afavorits, en masculí com en femení, en singular com en plural. La sillaba inicial molt sovint és escrita $\mathrm{Ca}$-, la qual cosa no canvia la pronúncia.

El més conegut dels Querol és la penya que sosté el Castell de Carol, al terme municipal de Porta a la Cerdanya (Cheirol en 1011, Cherol en 1023); ha donat el seu nom a la llarga Vall de Carol, que s'estira des del Port de Pimorenç fins a Enveig. La Punta de Querol és un cim andorrà al nord-est de Canillo. Dos llocs es diuen Carol, l'un a Sureda i l'altre a Montferrer (locum qui dicitur a Cherol en 1156).

En masculí plural, trobem un Carols al terme municipal de Glorianes; un altre al terme d'Odelló (loco uocato Querolls, 1339).

En femení singular, Carola apareix als termes de Vallcebollera, Serdinyà, Mosset $\mathrm{i}$ Cornellà de Conflent.

En femení plural, Caroles es veu als termes de Real (Capcir) i Cornellà de Conflent.

Una sufixació en -ariu dóna Caroler a Prats de Molló.

\section{ALTRES SUFIXOS}

Veiem dues vegades Caraig, a Montoriol en Rossello (stagno de Karaig en 1183) i a Quillà, on es tracta d'un poblet desaparegut (Carag en 1006). Un sufix de localització - egi s'afegeix a la forma determinada, d'on karria-egi.

Amb un sufix romànic, que pot ser -etu o-ittu, Caret es presenta als confins dels pobles conflentesos de Mantet i Nyer. 
A més karri intervé en determinants de denominacions compostes: $B a C$ del Quer de l'Àliga, Ras de Carlit, Vinya del Quer, etc.

KE

Aquesta posposició que apareix en alguns topònims medievals, correspon fonèticament a les posposicions basques - $k i$ indicant la matèria constitutiva o l'origen, $\mathrm{i}$-kei/-gei indicant la matèria o la destinació (però no a -ke que és un sufix verbal).

L'existència de $-k i \mathrm{i}$-kei en les inscripcions ibèriques no resulta significativa, donada la brevetat del grup.

Segons que -ke va seguit o no d'una vocal temàtica $-u$, l'evolució fonètica romànica đóna resultats molt diferents: pensem en pace que đóna pau; dici(t), diu; però: laq(u)eu, llaç; brachiu, braç. A més, en cas d'accentuació proparoxitònica, tenim resultats més particulars, que examinarem en primer lloc.

\section{Aro. Auda}

En aquest primer gup, trobem dos hidrònims.

La Vall d'Aro, al nord de Sant Feliu de Guíxols, és mencionada Arace en 899. Es pensa en el basc aroki, «venint del cercle»; la part superior de la Vall d'Aro descriu un mig cercle abans de prendre la direcció del mar.

El riu Auda té la seva font al Capcir; és atestat des de l'Antiguitat Atax-Atacis (Plini) o Atax-Átagos (Estrabó). Es veu la intenció d'introduir en les declinacions llatines $i$ gregues un vocable autòcton que podia ser Ataki: Mela anomena Atacini els riberencs de l'Auda; el riu porta el nom de Atace en 850. En 1035 una grafia, flumen Ataze, evidencia l'espirantització de $k$, amagada per la grafia clàssica. En 1070 una atestació, Aditum fluuium, manifesta la metàtesi de les dues síllabes posttòniques; no és una forma Ataki, sinó una forma Akita, que és llatinitzada maldestrament: una z intervocàlica podia resultar tant d'una $d$ (Benedictu/Benezet/Benet) $\mathrm{com}$ d'una k ( $+e, i)$ (uicinwivezin'vei). Partint de Ákita, la forma Auda és regular (cf. plaure de plácere, deume de décimu, etc.). L'ètim és el basc ate, «porta, clivella d'entrada, bretxa...». Ataki significa, doncs, «venint de la bretxa»: recordem que el curs superior de l'Auda és perpendicular a les serres pirinenques, i que les travessa pels congostos de Sant Jordi i de Pedra-Lis.

El mateix terme ataki entra en toponims compostos, tals com el poble d'Axat (Adesate en 955) situat entre els dos congostos abans anomenats, i que pot representar *atakiate; o el riu del Fenollet, I'Adesig (Adadig en 1142), hereu de *atakiegiu. 
La reducció de $-k i$ final a la semivocal $w$ és més freqüent.

Escriu, llogarret del municipi de Brocà, al Berguedà, es presenta sota la forma Ascarice en 938. Azkarai-ki té el sentit de «venint de la penya molt altan; el lloc se situa sobre la Serra de Cadí.

Estamariu (o Estimariu) designa tres llocs diferents. El poble de l'Urgellet apareix en 839 amb la forma Stamariz. Una masia al nord-est de Ripoll es manifesta en 888 amb les formes Stamarice, Stamarez i Tamarice. No coneixem mencions antigues de l'Estamariu vallespirenc. L'origen no apareix gaire clar: ezti-amai-ari-ki, «per l'ocupació de la fi de la mel». Es tractava dels últims llocs on es podia recollir mel?

Madriu (Matrice en 815) designa un afluent de la Riera d'Alp (Cerdanya), un riu andorrà que recorre la Vall Civera, i també intervé en el nom del Roc de la Madriu a Tues (Conflent). Pot ser, amb aferesi de la $o$ inicial, (o)ma ateri ki, «venint d'un turó sec».

Beliu (Belis en 880 ) era un poblet del Baridà. Belai designa una pastura closa; el conjunt belaiki és el nom de la belladona.

Esperaríem una $e$ com a vocal tònica, tal com la trobem en la menció Stamarez; el tancament en $i$ pot ser degut a la semivocal final o a una romanització tardana.

\section{Esduç. Taulís}

Esduç (Exeduce en 883), ermita del municipi de Cerc (Urgellet), representa etxe, «casa» probablement seguit de toki-u; el conjunt significaria «el lloc de la casas.

Llǔ̧ (Loci en 840) és un llogarret de Santa Llocaia (Cerdanya). Amb aferesi de la vocal inicial, correspon fonèticament a oru-ki-u, «venint del solar». El mateix ètim figura al radical d'Olopte (Olorbite en 839).

Sanarús (Sannaruz en 979), llogarret situat al nord-est de Ripoll, pot ser, amb aferresi de la vocal inicial, etxen-aro-ki-u, «del cercle de cases». El topònim cerdà Saneja s'anomena Exenegia en 839.

Taulis, poble del Vallespir, presenta la menció Teulicius en 853, Teuolici en 991. Domina un dels congostos que escanyen la Ribera Ampla. Es poden proposar explicacions romàniques; però no es pot negligir que en basc ateburu, "gropa del congost” correspondria el romànic *(a)tebol.

Aquí també constatem el tancament de les vocals romàniques tòniques sota l'acció de la desinència. 
Només trobem en les inscripcions ibèriques el grup bastikino.

El sufix basc-giño/-kiño té el sentit de «fins a». Sembla que intervingui en les formes antigues Barkino, Ruskino, de les quals l'Edat Mitjana havia de fer Barcelona i Rosselló. (I)barkino significa «fins a la valls; (e)rruitzki. no, «fins a l'escarpa», designacions que justifica la topografia dels llocs.

\section{KO}

Frequient en inscripcions ibèriques, aquest grup és massa curt perquè sigui significatiu.

El sufix basc - $k o$ indica la situació; és la marca del genitiu de situació. Intervé en molts topònims: Canigó (gaineko), Carcolze (karrikobite), Cotlliure (caukoliberri), Pincaró (pinu karriko une), Gorguja (gorko egia), Rigolisa, Eragolissa en 946 (erreko lezea), etc.

El nom del riu Tec (Tecum, Plini) podria resultar de ateko, ade la bretxa», donat el trajecte vallespirenc del curs.

\section{KORRI}

Encontrem en iber el grup untikorrisarwi. Aquest terme korri esdevé regularment gorri, «roig» en basc modern. Acabem de notar-lo en formacions com karriu-korri-be, «al peu de la penya roja».

Ens interessa particularment el cas de Begur, poble empordanès situat a dos quilòmetres de la costa. Trobem en 1056 la menció ipsum castrum de Begur. En la seva Guia de la Costa Brava ${ }^{18}$. Josep Pla tracta de Begur en aquests termes: «Los primeros vestigios históricos escritos sobre Bagur son de la época feudal [...] la peña tiene un color gris de sombra tocado por un hálito ferruginoso..." Aquest matís rogenc apareix particularment als rocs del riu que voreja Begur. Per això interpretem Begur per ibai-gorri-u, «riu roig», varietat pre-romànica dels hidrònims Llobregat (rubricatu), nombrosos al país. Va haver-hi aferesi de la $i$ inicial, reducció de ai a $e$, diftongació condicionada per yod de la $o$ tònica i monoftongació en $u$ (cf.podiu dóna puig). El terme és idèntic a Baigorri de Baixa Navarra; quan aquest hidrònim és llatinitzat en 1186, pren la forma Baigur ${ }^{19}$.

18 J. PLA, Guia de la Costa Brava. Barcelona 1948, p. 217-224.

19 J. CARo B ARosa, Materiales para una historia de la lengua vasca en su relación con la latina. Salamanca 1946, p. 124. 


\section{$\mathrm{T} / \mathrm{D}$}

\section{(I)TO}

El basc ito significa «negat» i també «amagat». No hem trobat aquest grup en iber.

Toluges (908 Tulogias, 951 Tologias, 1119 Toluges) és un poble rossellonès al sud-oest de Perpinyà. Es pot pensar en el basc ito-oru, «solar negats (oru representa un antic olu) seguit pel sufix localitzador-egi-a. Toluges significaria, doncs, «lloc del solar negat». Efectivament, no gaire lluny del curs del riu Bassa, Toluges és en un clot recorregut ara per les agulles d'assecament; en altre temps podia ser un aiguamoll. A l'oest, amunt del poble, un Jloc encara es diu aLa Sanyas.

Tolon fins al segle XI (934 castro Tolone, 977 castro Tholone, 1019 Tolono castro) va designar el lloc on es troba ara el poble de Peralada, a l'Empordà. Una carta del 844 ens indica el canvi de nom: «et postea nomen Petralata ibi miserunt quae antea a paganis Tolon, siue terra mortua, uocauerunt ...». Aixi Tolon significa aterra morta» en la llengua dels upagans». Quins eren aquells pagans? Al segle IX podríem presumir que es tracta dels àrabs; però sembla impossible de justificar per l'àrab la interpretació del terme. Ara bé, si ens fixem en l'adverbi antea, que evoca una època més antiga, podem pensar en els bascs.

El romanista que compara topònims tals com Tolon (i Toulon de Provença), Tolosa (i Toulouse de Llenguadoc), Toledo, etc, té la temptació de reconèixer sufixos romànics familiars -one, -osa, -etu, etc, i d'aillar un radical tol... que l'embarassa molt.

Al contrari, el basc ens convida a tallar després de (i)to, knegats; per exemple, belar significa «herba», i itobelar és una «herba que creix dins l'aigua». Tolon ens deixa un segon element lone, que, després de la caiguda de $n$ intervocallica, ens fa esperar el basc modern $\operatorname{lo}(h) i$, afang, llim, fanguer». El conjunt Tolon té el sentit de «fang negat», terra que no convé al conreu, el que justifica la designació de terra mortua. Peralada se situa a la confluència dels rius Llobregat i Orlina.

AI Baridà trobem un altre Tolon. És un llogarret de Bellver, que actualment es diu Telló, però les mencions antigues (Sancte Marie Tollonensis en 839, pago Tollonense en 890, Tollone en 958 i 983, pago Tolonense en 999. Tolon en 1040) ens ensenyen un vocalisme primitiu $o$, dissimilat més tard per la $O$ tònica. Ben entès, el Toulon provençal pertany al mateix grup. I Tolosa s'explica per ito-luzea, «la planura negada»; Toledo, per ito-lito, «fondalada negada». 
La base ito encara apareix a la síllaba inicial de tres topònims, dos pobles, Tues i Tuïr, i Tuèvol, llogarret de Talau. Tues i Tuèvol són a l'alt Conflent; Tuïr, al Rosselló. Tues presenta la forma Tobese en 878; Tuïr, Tuuirium en 985; Tuèvol, Tobecale en 864.

El primer topònim Tobese ens suggereix un origen ito-bizi, bizi posseint el sentit de «vida», però també d'«aigües vives». S'hauria d'entendre «negat o amagat per les aiguies vives»; notem que Tues és una estació coneguda per les seves fonts termals.

Per Tuïr pensem en ito-bere, «propens a ser negat», amb una vocal temàtica romànica $u$. Tobéreu dóna Tobériu per hiatus, i Tobíriu després de la diftongació de la e tònica sota l'acció de la yod i reducció a $i$. (cf. mediu/mig). Com en el cas precedent, la $b$ espirant és absorbida per la $o$, que llavors es tanca en $u$ per hiatus. Tü̈r és enclotat al peu d'un pendís que puja molt de pressa a l'oest $i$ al sud: a dos quilòmetres al sud, Santa Coloma de Tuïr de més de setanta metres; a un quilòmetre a l'oest, la carretera de Castellnou puja quaranta metres.

Per Tuèvol, itobekale pot ser «graner sota l'aiguat»; la posposició - be té el sentit de «sota, al peu de».

\section{(I)TURRI}

Iturri, que significa efonts, intervé sovint en toponímia. Les inscripcions ibèriques presenten grups tals com banulirrbaiturrane o kaisanwlirrbaiturra.

El poble cerdà de Dorres ofereix les mencions Edors (1011), Edorres (1163), Dorres (1220); afegeix a iturri una s romànica de plural. Diverses fonts termals brollen a Dorres, i el Ilogarret veí es diu Les Escaldes.

El nom d'Andorra ja apareix el 839 en l'acte de consagració de la Seu d'Urgell. No pot ser la forma primitiva, perquè el català redueix a $n$ el grup primari nd (mandare dóna manar); quan un grup nd s'encontra en català, es pot afirmar que és secundari (semita dóna senda). Doncs, hem de postular una forma més antiga $\mathrm{i}$ no atestada de l'estil de *Ameturra (existeix en Biscaia un Amiturria), que donaria perfectament Andorra. Aquell *Ameturra pot resultar de ama-iturr- $a$, «la font mare», això és degut al fet que els dos Valira del Nord i de l'Oest s'uneixen a Andorra per donar el riu principal.

La Tor de Querol presenta atestacions loco de la Torre el 913, in ipsa Torr el 983. No és impossible que tor representi el llatí turri, «torre», però no hi ha cap torre a La Tor, sinó molt més amunt, al poblet de Querol, que pertany al municipi de Porta. Per això, és probable que es tracti del basc iturri amb una afêresi de la vocal inicial prou precoç perquè no hi hagi hagut sonorització de la $t$. 
El poblet de Dòrria, al nord-oest de la Vall de Ribes, és representat en el 839 per la forma Duaria. Aquesta forma ofereix una doble dificultat si es vol relligar-la a iturria, «la font»: la $a$ i la $r$ senzilla. Si la $a$ fos una cacografia per una primera $r$, tot es tornaria perfectament normal...

Aquí limitarem l'extensió d'aquesta contribució, que, amb dues lletres inicials, ja ens proporciona un material toponímic molt important. 


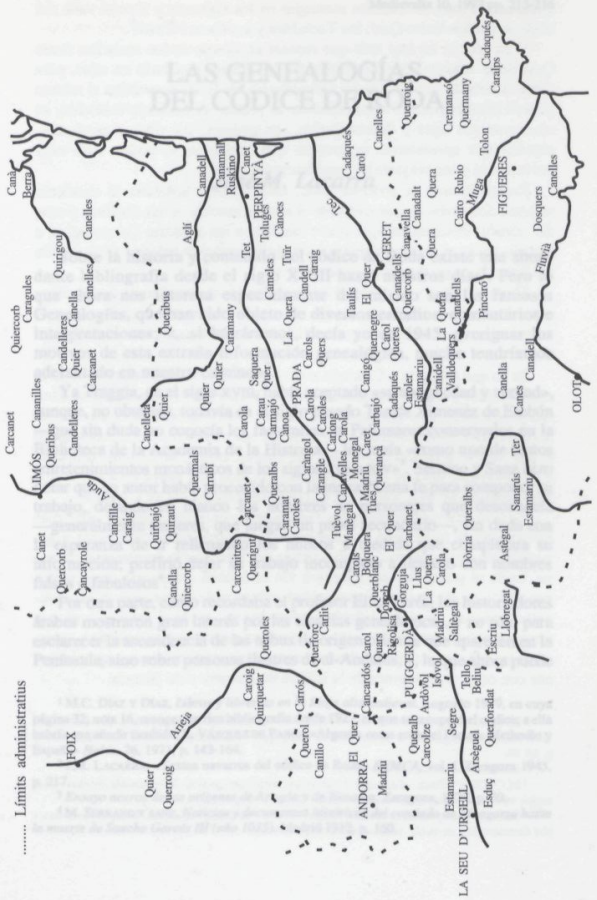

